\title{
Rhinovirus replication and innate immunity in highly differentiated human airway epithelial cells
}

\author{
Stephanie M. Warner, Shahina Wiehler, Aubrey N. Michi and David Proudº
}

\begin{abstract}
Background: Human rhinovirus (HRV) infections are the primary cause of the common cold and are a major trigger for exacerbations of lower airway diseases, such as asthma and chronic obstructive pulmonary diseases. Although human bronchial epithelial cells (HBE) are the natural host for HRV infections, much of our understanding of how HRV replicates and induces host antiviral responses is based on studies using non-airway cell lines (e.g. HeLa cells). The current study examines the replication cycle of HRV, and host cell responses, in highly differentiated cultures of HBE.

Methods: Highly differentiated cultures of HBE were exposed to initial infectious doses ranging from $10^{4}$ to $10^{1} 50 \%$ tissue culture-infective dose $\left(T_{C} I_{50}\right)$ of purified HRV-16, and responses were monitored up to $144 \mathrm{~h}$ after infection. Viral genomic RNA and negative strand RNA template levels were monitored, along with levels of type I and II interferons and selected antivirals.

Results: Regardless of initial infectious dose, relatively constant levels of both genomic and negative strand RNA are generated during replication, with negative strand copy numbers being10,000-fold lower than those of genomic strands. Infections were limited to a small percentage of ciliated cells and did not result in any overt signs of epithelial death. Importantly, regardless of infectious dose, HRV-16 infections were cleared by HBE in the absence of immune cells. Levels of type I and type III interferons (IFNs) varied with initial infectious dose, implying that factors other than levels of double-stranded RNA regulate IFN induction, but the time-course of HRV-16 clearance HBE was the same regardless of levels of IFNs produced. Patterns of antiviral viperin and ISG15 expression suggest they may be generated in an IFN-independent manner during HRV-16 infections.
\end{abstract}

Conclusions: These data challenge a number of aspects of dogma generated from studies in HeLa cells and emphasize the importance of appropriate cell context when studying HRV infections.

Keywords: Highly differentiated human airway epithelial cells, Human rhinovirus, Negative strand template, Interferons, Viperin, Viral clearance

\section{Introduction}

Human rhinovirus (HRV) infections are responsible for over $50 \%$ of common cold-like illnesses [1], and HRV is the most common virus triggering acute exacerbations of asthma and chronic obstructive pulmonary disease [2-4].

The primary site of HRV infection and replication in both the upper and lower airways is the human airway

\footnotetext{
*Correspondence: dproud@ucalgary.ca

Department of Physiology \& Pharmacology and Snyder Institute for Chronic Diseases, Cumming School of Medicine, University of Calgary, 3280 Hospital Drive NW, Calgary, AB T2N 4Z6, Canada
}

epithelial cell $[5,6]$, and it is thought that HRV-induced changes in epithelial biology contribute to symptoms. In support of this, HRV-infected human airway cells, grown either as undifferentiated cells in submersion culture, or as cells differentiated by culture at air-liquid interface (ALI), release proinflammatory chemokines and cytokines, several of which are also detected in airway secretions during HRV infections [7, 8]. HRV infections also trigger epithelial induction of a range of potential host antiviral molecules that may limit viral replication $[7,9,10]$.

Much of our understanding of how HRV replicates and induces host antiviral responses, is based on studies

(C) The Author(s). 2019 Open Access This article is distributed under the terms of the Creative Commons Attribution 4.0 International License (http://creativecommons.org/licenses/by/4.0/), which permits unrestricted use, distribution, and 
using non-airway cell lines (e.g. HeLa cells), or is inferred from studies of other picornaviruses. HRV replication requires virus entry into cells and genome release [11]. The viral polyprotein is then translated from the positive sense RNA genome and the viral RNA polymerase subsequently generates negative strand copies of the HRV genome. These negative strands serve as templates for replication of positive strand genomes for packaging in the virus capsid [12]. Thus, during RV replication, double-stranded RNA (dsRNA) is generated which, according to dogma, not only regulates levels of viral replication but also is recognized by pattern recognition receptors that mediate the induction of proinflammatory and antiviral responses [13]. Viral release from infected cells then occurs via cell lysis [12]. Although it is generally held that innate immunity plays a key role in regulating the outcome to HRV infections, it is thought that immune cells also play an important role in viral clearance [14].

Human airway epithelial cells can now be cultured to reproduce in vivo epithelial morphology, and can survive for months, permitting experiments of much longer duration than could be achieved with submersion cultures. We exposed highly differentiated cultures of human bronchial epithelial cells (HBE) to varying initial infectious doses of HRV and monitored responses for $144 \mathrm{~h}$. We show that, contrary to existing dogma, HBE clear HRV infections without the need for immune cells. In addition, we observed that levels of dRNA, assessed by quantification of negative strand template RNA, correlate temporally and quantitatively with maximal intracellular viral genome loads. In marked contrast, maximal levels of type I and type III interferon (IFN)s, as well as of some other host defense molecules, are not related to peak negative strand template levels but, rather, vary depending on the initial infectious dose of HRV used.

\section{Methods}

Isolation of human bronchial epithelial cells

HBE were obtained by protease digestion of dissected airways (main stem bronchus to 4th generation) as previously described [15], and stored in aliquots in liquid nitrogen until used. Each "n" value for experimental data represents the use of cells from a different individual donor.

\section{Air-liquid Interface culture of HBE cells}

HBE cells were cultured on $T 75 \mathrm{~cm}^{2}$ flasks (Costar, Corning Inc., Corning, NY) in Bronchial Epithelial Growth Medium (BEGM, Lonza, Walkersville, MD) supplemented with 5\% FBS for $72 \mathrm{~h}$ (Life Technologies, Burlington, Ontario, Canada). Cells were then fed every $48 \mathrm{~h}$ with BEGM without FBS. At $90 \%$ confluence, cells were lifted and seeded at $2.0 \times 10^{5}$ cells per insert onto
$1.12 \mathrm{~cm}^{2}, 0.4 \mu \mathrm{m}$ pore transwell inserts (Costar) coated with bovine collagen Type I/III (Advanced BioMatrix, San Diego, CA), and cultured in BEGM for $48 \mathrm{~h}$. BEGM was then removed and HBE were cultured using only basolateral PneumaCult-ALI differentiation medium containing 100X supplement, hydrocortisone, and heparin (Stemcell Technologies, Vancouver, BC, Canada), as well as fluconazole (Sigma-Aldrich, Oakville, Ontario, Canada) and penicillin/streptomycin (Life Technologies). Cells were fed basolaterally every $48 \mathrm{~h}$. Beginning 14 days after seeding, cells were washed apically once per week with PBS to remove excess mucus. Cultures were used for experiments at 5 weeks after transwell seeding.

\section{Viral propagation of HRV-16}

HRV-16 stock was propagated in WI-38 cells and purified by sucrose density centrifugation as described [16]. Purified HRV-16 was dialysed, using a $10,000 \mathrm{kDa}$ membrane, against $25 \mathrm{mM}$ HEPES/F12 media for $18-20 \mathrm{~h}$ at $4{ }^{\circ} \mathrm{C}$ to remove sucrose. Replication-deficient HRV-16 was generated by exposure to Ultraviolet light for $5 \mathrm{~min}$ as described [17].

\section{Human rhinovirus inoculation}

ALI cultures were infected apically with HRV-16 diluted in $25 \mathrm{mM}$ HEPES/F12 at $34{ }^{\circ} \mathrm{C}$ for $4 \mathrm{~h}$. Cells were then washed apically 5 times with $\mathrm{PBS}$ to remove noninternalized HRV-16 and maintained at $37^{\circ} \mathrm{C}$, feeding basally with PneumaCult every $24 \mathrm{~h}$. Shed HRV-16 was collected at appropriate time points by rinsing the apical surface of ALI cultures with $500 \mu \mathrm{L}$ PBS. Intracellular RNA was isolated for assessment of intracellular HRV levels.

\section{Immunofluorescence staining and microscopy}

ALI cultures were fixed in $4 \%$ paraformaldehyde (Alfa Aesar, Heysham, UK) for $15 \mathrm{~min}$ at room temperature. Cells were blocked and permeabilized with 10\% BSA, 5\% NGS, 5\% normal rabbit serum, 5\% normal mouse serum in PBS (0.1\% TritonX-100) for $2 \mathrm{~h}$ and rinsed in PBS. Cells were stained with mouse anti- $\beta$-tubulin (Sigma) at $1: 200$ in $2 \%$ BSA in PBS (0.1\% TritonX-100) overnight at $4{ }^{\circ} \mathrm{C}$. Cells were washed 3 times with PBS $(0.1 \%$ TritonX-100) and stained with $\alpha$-mouse AlexaFluor488 (ThermoFisher Scientific, Waltham, MA) at 1:200 in 5\% BSA in PBS $(0.1 \%$ TritonX-100) for $2 \mathrm{~h}$ at room temperature. Cells were washed 5 times with PBS $(0.1 \%$ TritonX-100) and re-blocked with $10 \%$ mouse serum in PBS for $3 \mathrm{~h}$. Mouse anti-dsRNA antibody (Scicons, Szriak, Hungary) was labeled with an AlexaFluor555 labeling kit (ThermoFisher), pre-absorbed at 1:200 in 5\% BSA, 5\% normal mouse serum in PBS for $1 \mathrm{~h}$, and added to cells overnight at $4{ }^{\circ} \mathrm{C}$. Cells were washed 3 times with PBS (0.1\% TritonX-100) and nuclei subsequently stained 
with DAPI (ThermoFisher) at 1:50,000 for $20 \mathrm{~min}$. Inserts were mounted using FluorSave (EMD Millipore) and imaged on a Leica TCS SP8 resonant scanning confocal microscope (Leica, Wetzlar, Germany) with Leica LasAF software.

\section{Histology}

HBE were fixed in $10 \%$ neutral buffered formalin, embedded in paraffin, and sectioned to $4 \mu \mathrm{m}$ thickness onto Superfrost plus slides. Alcian blue and hematoxylin staining was performed by de-paraffinization in two changes of xylene and rehydrating through graded ethanol solutions (100, 95, 70\% EtOH). Alcian blue 8GX (Sigma) in 3\% acetic acid solution was added for $2 \mathrm{~min}$ and rinsed in water for $2 \mathrm{~min}$. Hematoxylin Gills II (Leica Biosystems) staining was performed for $5 \mathrm{~min}$ and rinsed in warm tap water for $5 \mathrm{~min}$. Slides were dehydrated through reverse graded ethanol solutions (95, $100 \% \mathrm{EtOH}$ ) and cleared in two changes of xylene before applying coverslip with Permount (ThermoFischer).

\section{RNA extraction and real-time qRT-PCR}

Total cellular RNA was isolated with the NucleoSpin RNA kit (Macherey-Nagel GmbH \& Co, Duren, Germany), which included homogenization of the lysates, an on-column DNase digestion and elution in RNase/DNase free water. RNA concentration and purity was determined on a NanoDrop 2000 spectrophotometer. HRV-16, viperin, CXCL10, ISG15, IFN $\lambda 1$ and IFN$\beta$ mRNA expression were assessed by real-time RT-PCR using specific primers and a TaqMan probe for each gene. For each mRNA, a synthetic first-strand cDNA was used to generate standard curves to permit absolute quantification. Data were expressed as femtograms calculated from the standard curve. For HRV-16, data were converted to copy number. For positive sense genomic RNA, the detection limit of the RT-PCR system corresponded to a total copy number of $10^{6}$.

Viral RNA from apical wash samples were isolated with the QIAamp Viral RNA Mini Kit (Qiagen, Mississauga, Ontario, Canada) and subjected to quantitative RT-PCR using primers and probe directed to the $5^{\prime}$-untranslated region of HRV-16.

\section{Negative Strand template primer design}

This assay uses a chimeric primer for reverse transcription containing a non-viral sequence at the $5^{\prime}$ end of the specific sequence targeting the negative strand of HRV16. This non-viral sequence is then used as a primer to selectively amplify the negative strand specific cDNA at the PCR stage. We validated that this assay was selective using synthetic, HPLC-purified negative and positive strand oligonucleotide sequences that spanned the sequences used for the assay. We confirmed not only that the primer system for negative strand did not show a positive signal when used with an excess of positive strand, but also that that detection of serial dilutions of negative strand was not affected by the presence of a multi-fold excess of positive strand sequence.

One microgram of RNA was reverse transcribed with Maxima reverse transcriptase with $\mathrm{RNase} \mathrm{H}+$ activity (Invitrogen, Carlsbad, CA) and the chimeric primer (Table 1). The non-viral sequence was taken from within the Escherichia coli genome and a Blast search confirmed the lack of any homology within the rhinovirus genome. To remove any potential carry over RNA, cDNA was RNase treated with an RNase cocktail (Invitrogen). cDNA was then purified using the QIAquick PCR Purification Kit (Qiagen, Hilden, Germany). Realtime PCR was carried out with a HRV-16 specific forward primer and probe, directed within the VP1 region of HRV-16, and the non-viral reverse primer. A synthetic first-strand cDNA standard was used to quantify the amount of template present. Absolute values were used to determine copy number.

\section{Elisa}

CXCL10 was measured by ELISA using matched antibody pairs (PeproTech, Rocky Hill, NJ). IFN- $\lambda 1$ and IFN- $\beta$ ELISAs were from R\&D Systems (Minneapolis, USA).

\section{Results \\ Epithelial cultures}

HBE cultured at air-liquid interface (ALI) for 5 weeks using PneumaCult-ALI differentiation medium show a morphology that resembles bronchial epithelium in vivo with a pseudostratified columnar structure containing well-defined goblet cells and numerous ciliated cells

Table 1 Primer and probe sequences used for the negative strand HRV-16 RT-PCR reactions

\begin{tabular}{lll}
\hline Name & Purpose of oligonucleotide & Sequence \\
\hline Neg-Tag-cDNA & Chimeric RT primer & 5'-ATCAGCGATGCCGAACGTATGGCAGCATGGGCAACCT-3' \\
Neg-HRV16-For & Real-time PCR Forward Primer & 5'-TGCTGATGCAATACTCAAAAAGG-3' \\
Tag-Rev & Real-time PCR Reverse Primer & 5'-ATCAGCGATGCCGAACGTAT-3' \\
Neg-Probe & Real-time PCR Probe & 5' FAM-TGAAAAGCGAGGGA-MGB3'
\end{tabular}

Underlined nucleotides denote non-viral tag sequences 
(Fig. 1). These 5-week cultures show an increased height and greater cilia coverage compared to typical 3-week cultures (not shown).

\section{HRV-16 infection does not cause overt cell toxicity in HBEs}

Highly differentiated cultures of HBE showed no evidence of overt toxicity at any point during infection. Histological evaluation of cultures exposed to either medium or to $10^{4} \mathrm{TCID}_{50}$ of HRV-16 when studied after a $144 \mathrm{~h}$ infection period (Fig. 2), showed no obvious differences, either between the two treatments or when compared to basal 5 week cultures (Fig. 1a).

\section{HRV genomic RNA levels in response to varying infectious doses of RV-16}

HBE from 4 different lung donors were infected with doses ranging from $10^{4}$ to $10^{1} 50 \%$ tissue cultureinfective dose $\left(\mathrm{TCID}_{50}\right)$ of HRV-16, and intracellular and shed levels of HRV genomic RNA were monitored with time by RT-PCR and expressed as total copy number (either in all cells from an insert or as total amount released). The timing of peak levels of intracellular genomic RNA varied, occurring later with lower infectious doses (Fig. 3a). Despite this, the peak copy number of genomic HRV observed was similar regardless of initial infectious dose. Interestingly, by $144 \mathrm{~h}$ after infection, HRV viral genome within the cells had declined to undetectable levels at all infectious doses except $10^{4}$ $\mathrm{TCID}_{50}$, where detection of residual burden was limited to a single donor.

HRV shedding from infected HBE occurred exclusively at the apical surface, with no detectable virus in basolateral medium. For each initial infectious dose, the time course of peak levels of HRV shedding mirrored those for intracellular virus, suggesting a "steady-state" between intracellular virus and the rate of shedding (Fig. 3b).
Again, shed virus levels returned to undetectable by $144 \mathrm{~h}$ post-infection, except for the same single donor infected with $10^{4} \mathrm{TCID}_{50}$ of HRV-16. To confirm that virus measured by RT-PCR reflected infectious virions, HRV in apical washes from cells infected with an initial dose of $10^{4} \mathrm{TCID}_{50}$ was measured by viral titer assay and showed the same pattern of viral load (not shown).

\section{Generation of negative strand viral RNA}

To understand the relationship of dsRNA to HRV replication and innate antiviral immunity, we initially performed immunofluorescence confocal microscopy on our densely ciliated cultures (Fig. 4a) with a monoclonal antibody directed to dsRNA [18] using cells exposed to $10^{4} \mathrm{TCID}_{50}$ of HRV-16. No fluorescence signal was observed in non-infected HBE or in HBE exposed to replication-deficient HRV-16 (not shown). In cells infected with HRV-16, perinuclear dsRNA staining was observed $24 \mathrm{~h}$ post infection (Fig. 4b). Interestingly, staining was restricted to ciliated cells (Fig. 4c). To determine percentage of total cells positive for dsRNA, cells from each of 4 donors were used, and three different fields of view for each donor were assessed. A reticule was used to define fields of view and percentage of total cells in the field (based on DAPI nuclear staining) that were positive for dsRNA was recorded. Using this method an average of only $4-6 \%$ of total cells showed positive staining for dsRNA.

We next developed an assay to specifically quantify negative strand template RNA, expressed as total copy number, as an index of levels of dsRNA. The temporal pattern of negative strand template production with initial infectious dose closely mirrored levels of positive strand genome (Fig. 5). As was seen for positive strand, similar peak intracellular levels of negative strand RNA were observed regardless of the initial dose of virus used for infection. However, in all cases, levels of negative
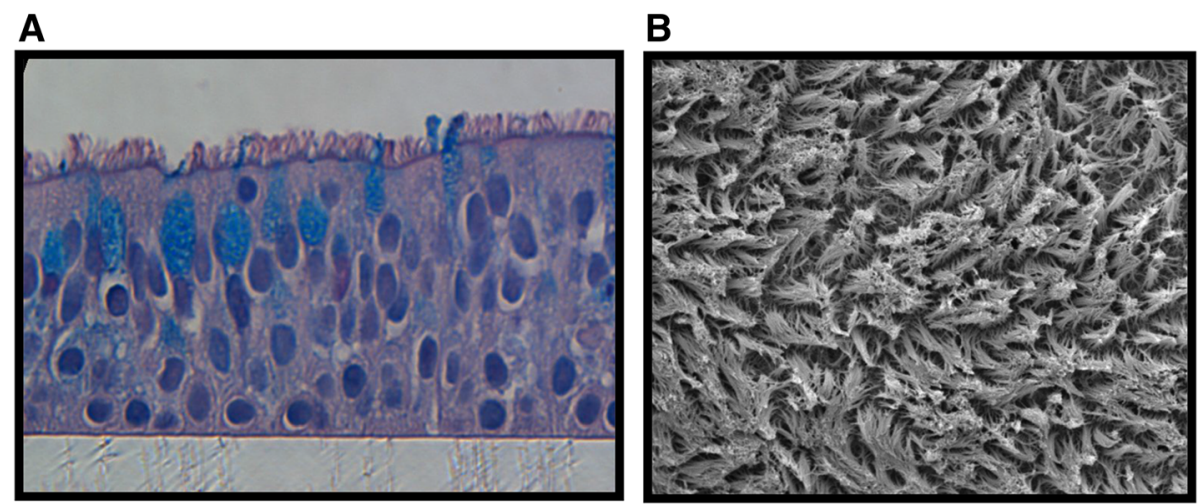

Fig. 1 Morphology of highly differentiated human bronchial epithelial cultures. a Histology of HBE cultures showing a pseudostratified morphology with numerous cilia. Goblet cells are shown using Alcian blue staining. b Scanning electron micrograph demonstrating a dense blanket of cilia 
A

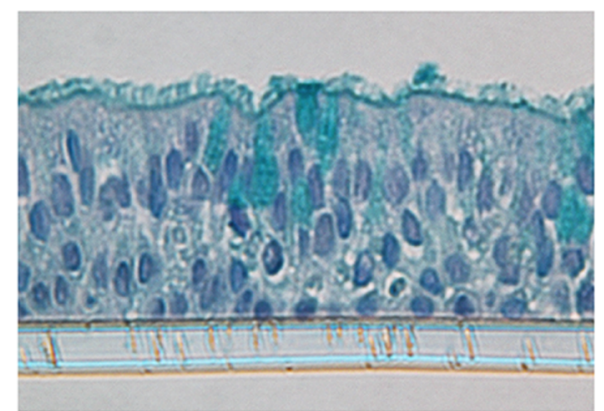

B

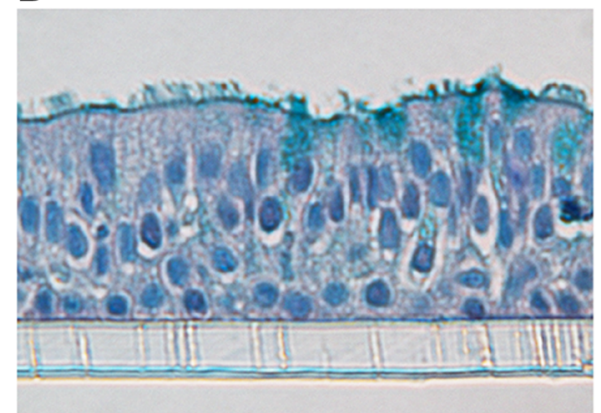

Fig. 2 HRV-16 infection does not cause overt epithelial damage. Histology of HBE cultures at $144 \mathrm{~h}$ after exposure to a) medium control or b) $10^{4}$ $\mathrm{TCID}_{50}$ of HRV-16

strand were approximately 10,000-fold lower than those of positive strand genome.

\section{Relationship of dsRNA to production of host defense molecules}

We then used the same negative strand copy number data to assess the relationship of dsRNA levels to production of a number of other molecules from the same cultures. In contrast to the close association between levels of negative strand template and genomic positive strand, no such relationship was observed for production of IFNs. Levels of intracellular mRNA for IFN- $\lambda 1$ and IFN- $\beta$, were temporally related to those of negative strand template (Fig. 6), but did not show a quantitative relationship. Instead, levels of IFN mRNA declined with the initial infectious dose of HRV-16 used. Levels of secreted IFN$\lambda 1$ and IFN- $\beta$ proteins, which were released dominantly at the apical surface, showed a similar pattern, although, depending on infectious dose of HRV, peak protein secretion occurred later than maximal mRNA levels (Fig. 6). Because levels of negative strand were already maximal at $24 \mathrm{~h}$ following infection with $10^{4}$ $\mathrm{TCID}_{50}$ of HRV-16, we performed separate experiments over periods up to $24 \mathrm{~h}$ after infection with this dose of HRV-16. Negative strand template was detectable by $8 \mathrm{~h}$ after infection and increased to peak levels at $24 \mathrm{~h}$ (Fig. 7), Interestingly, increased expression of IFN- $\lambda 1$ mRNA was not observed until $24 \mathrm{~h}$, when it was already comparable to the maximal level observed in Fig. 6.

Expression of mRNA and protein secretion (predominantly into the basolateral medium) of the chemokine CXCL10 showed similar temporal and quantitative patterns to the IFNs, with a clear relationship between levels of induction and initial infectious dose (Fig. 8). We have previously shown roles for viperin and ISG-15 in host defense to HRV infection $[9,19]$, so also examined mRNA expression for each of these molecules (Figs. 9 and 10). At the highest initial infectious dose $\left(10^{4} \mathrm{TCID}_{50}\right.$ of HRV16), peak expression of both viperin and ISG15 was slightly delayed relative to those of IFNs and CXCL10. Moreover, the dependence on infectious dose was less clear, as comparable viperin expression was observed
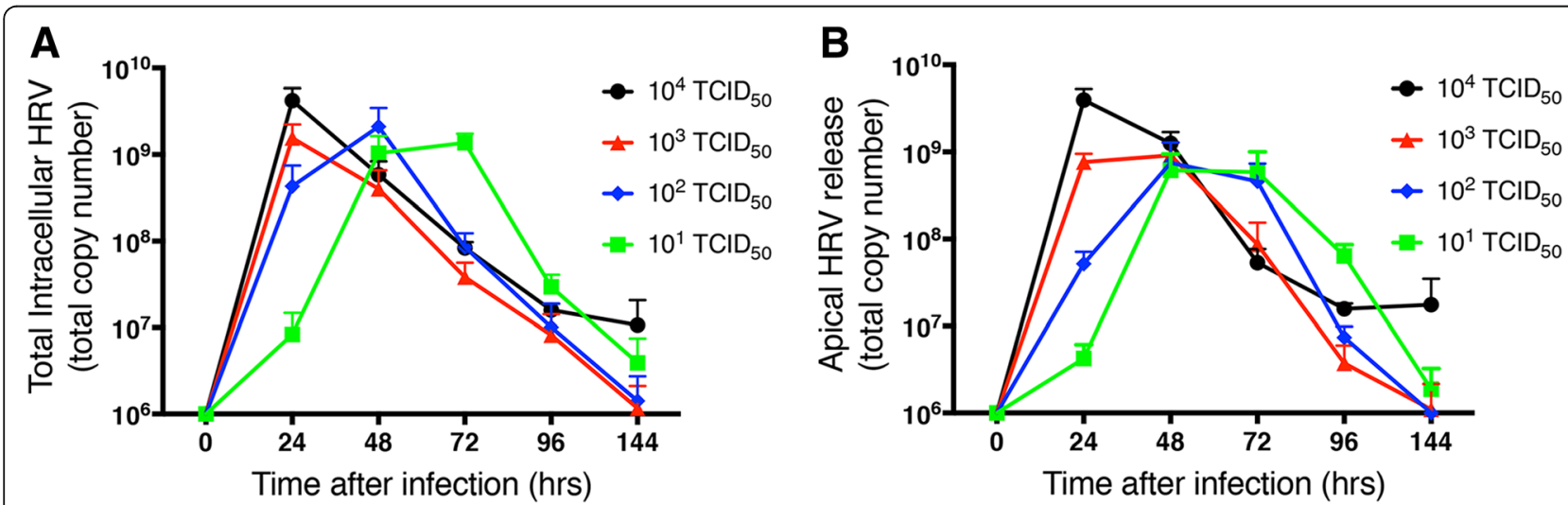

Fig. 3 Rhinovirus replication and clearance in highly differentiated HBE. Cells were infected with varying initial doses of HRV-16. a Total intracellular HRV genomic RNA levels with time. $\mathbf{b}$ Total levels of apically shed HRV genomic RNA with time. Data are mean \pm SEM from 4 different HBE donors. The limit of detection corresponded to a total copy number of $10^{6}$ 

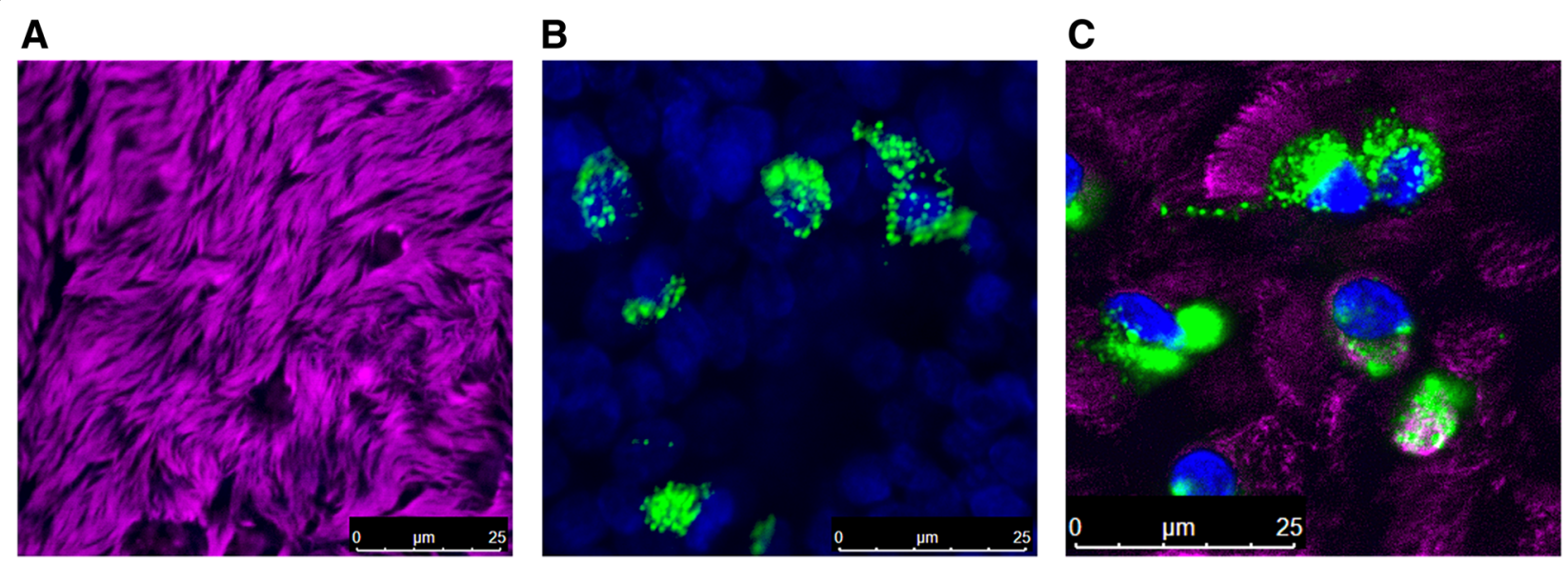

Fig. 4 Immunofluorescence staining of dsRNA in HBE infected with HRV-16. a Staining with an antibody to $\beta$-tubulin (violet) shows dense cilia on cultures of HBE. $\mathbf{b}$ Intracellular perinuclear staining for dsRNA (green) $24 \mathrm{~h}$ after infection with $10^{4} \mathrm{TCID}_{50}$ of HRV-16. Nuclei are stained blue with DAPI. c Co-staining of cilia (violet) and dsRNA (green) shows viral infection and replication occurs in ciliated cells. Scale bars are shown on each panel. Data are representative of $n=4$
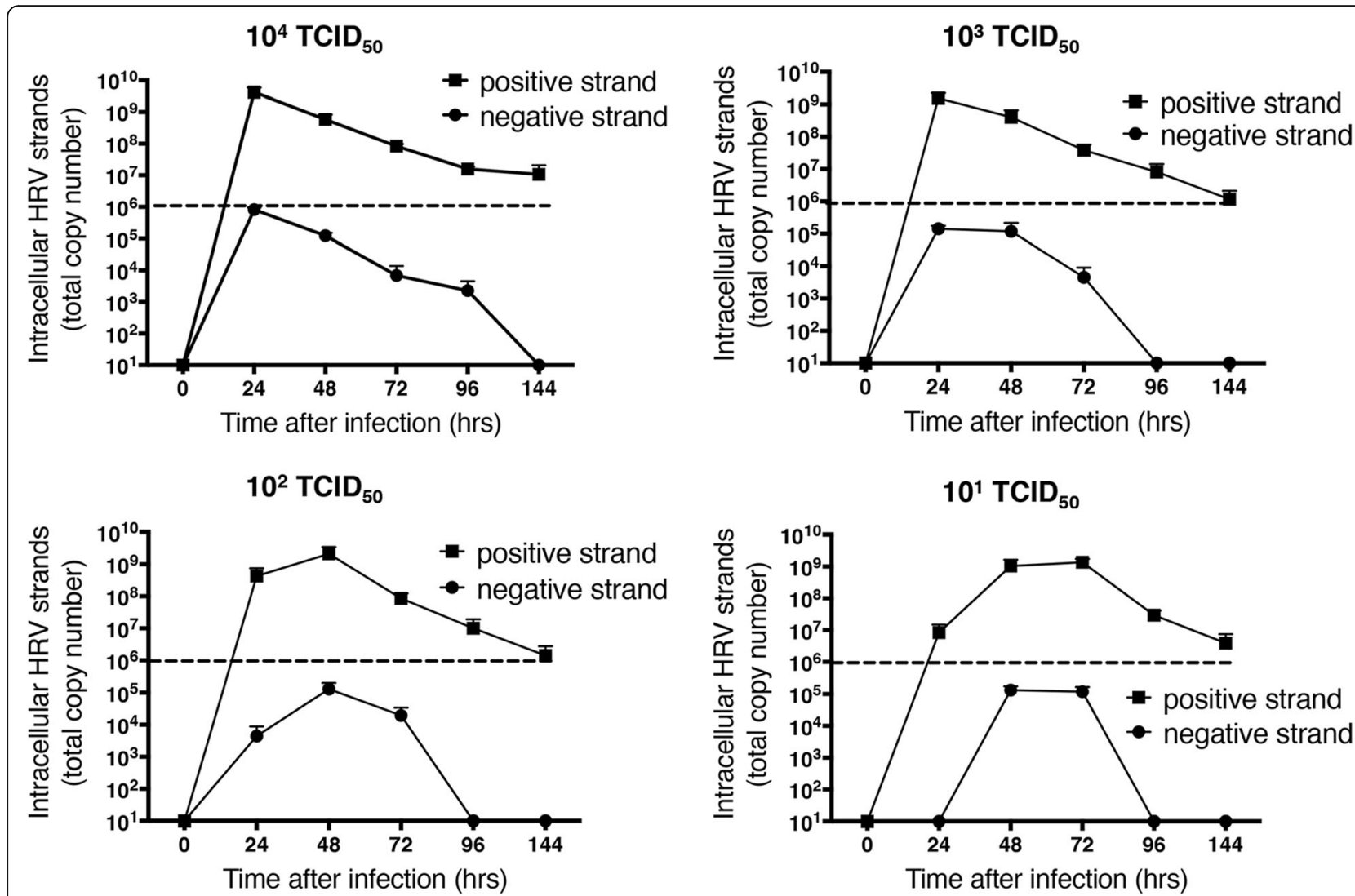

Fig. 5 Comparison of total copy numbers HRV-16 intracellular positive (genomic) and negative (template) RNA strands at multiple times after infection with varying levels of HRV-16. Data are mean \pm SEM from 4 different HBE donors. The dotted horizontal line shows the limit of detection for the RT-PCR for genomic RNA 

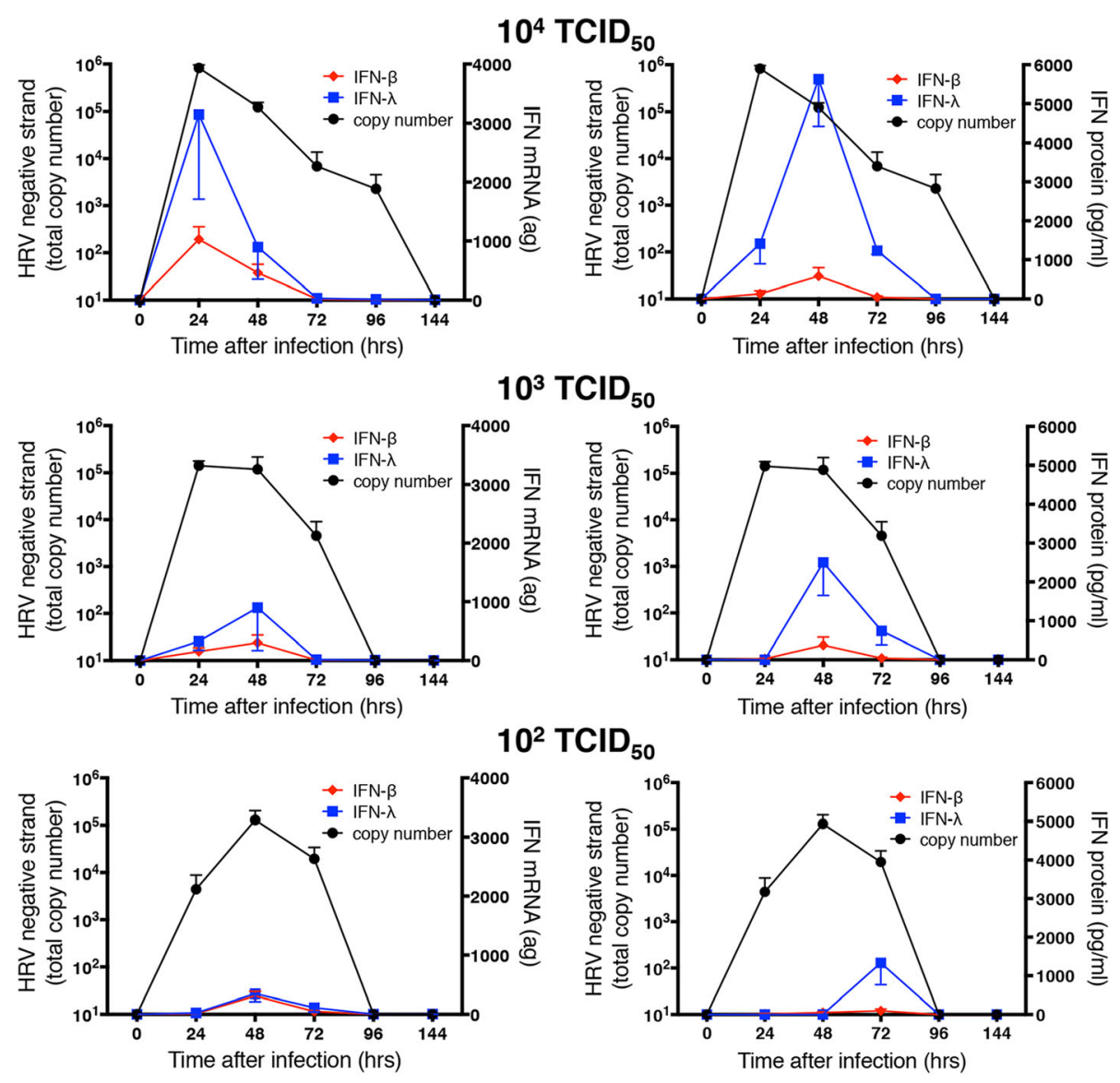

\section{$10^{1} \mathrm{TCID}_{50}$}
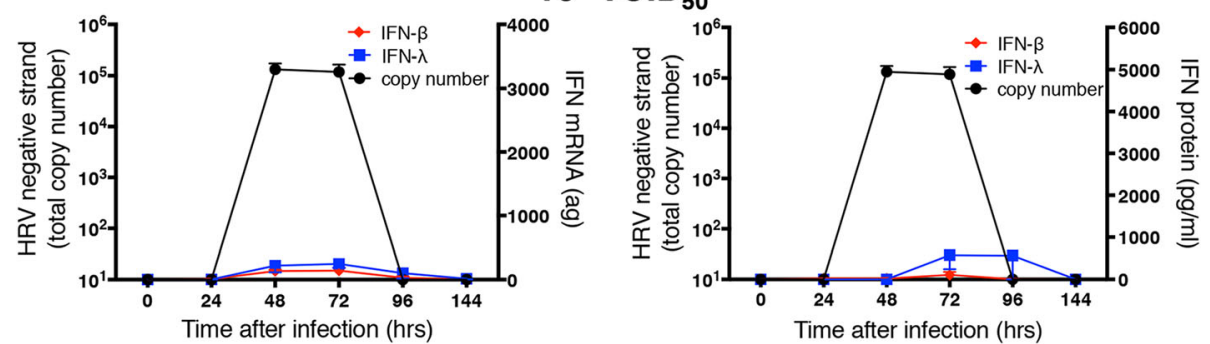

Fig. 6 Relationship between copy number of negative strand template (taken from Fig. 5) and mRNA or protein for IFNs. For each initial infectious dose of HRV-16, copy number of negative stand template is shown relative to levels of IFN- $\lambda$ 1 (blue) or IFN- $\beta$ (red). Left panels show IFN mRNA and right panels show apically secreted protein levels. Data are mean \pm SEM from 4 different HBE donors

at all initial infectious doses (except $10^{4} \mathrm{TCID}_{50}$ of HRV-16), and the reduction of ISG15 expression at lower doses was less marked. Generation of all of the host defense molecules examined depend upon viral replication, since exposure of $\mathrm{HBE}$ to $10^{4} \mathrm{TCID}_{50}$ of HRV-16 that was rendered replication deficient by exposure to UV light did not induce epithelial expression of any of the molecules studied (not shown).

\section{Discussion}

The HeLa cervical carcinoma cell line was invaluable for the development of vaccines against poliovirus [20], and the ease of infection of HeLa cells by picornavirus family members has led to the frequent use of these cells for studies of picornavirus replication. The physiological relevance of such studies of HRV replication must be questioned, however, since HRV selectively infects the airways. HRV infection studies in vivo demonstrate that epithelial cells are the natural site of HRV infection and replication $[5,6,21]$, and the use of human airway epithelial cell lines [22], and subsequently primary $\mathrm{HBE}$ grown in submersion culture [23, 24], or at ALI [25, 26], have provided important insights into the inflammatory and innate immune responses to HRV infection. HBE in 


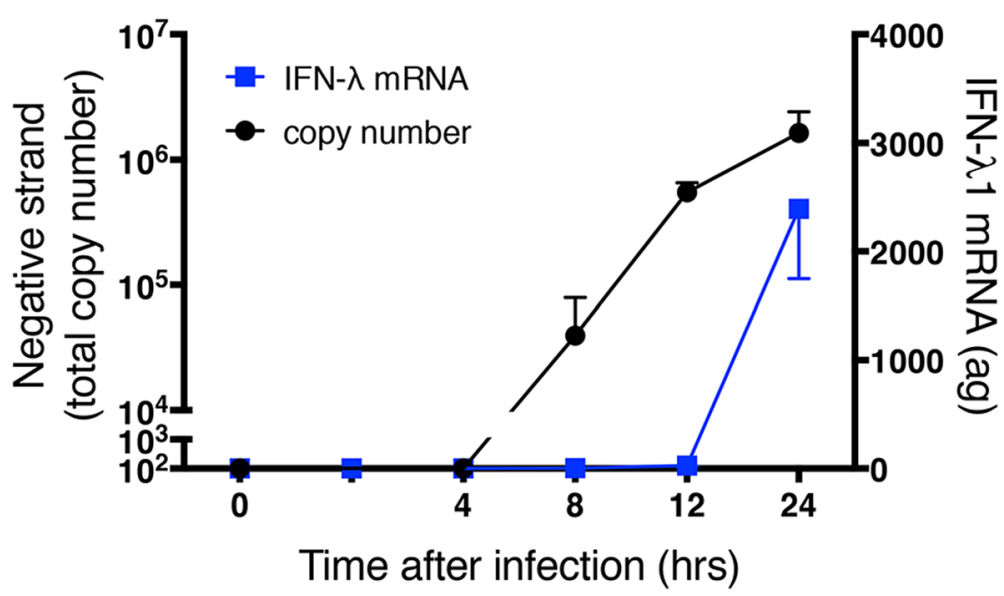

Fig. 7 Negative strand copy number and levels of mRNA over the first $24 \mathrm{~h}$ after infection with $10^{4} \mathrm{TCID}_{50}$ of HRV-16. Data are mean \pm SEM from 4 different HBE donors

submersion culture are not suited, however, for studying the complete HRV replication cycle, as confluent cultures cannot be maintained for extended periods. Initially, ALI cultures of HBE used cells grown in "bronchial epithelial differentiation medium" for 3 weeks yielded cultures that were multi-layered and expressed some cilia but did not reproduce the in vivo pseudostratified columnar morphology [25, 26]. By contrast, 5week ALI cultures grown in PneumaCult medium recapitulate in vivo morphology. Moreover, these cultures can be maintained for months at ALI, permitting the current studies examining the HRV replication cycle in response to varying initial infectious doses of HRV. Although well differentiated cultures of human airway epithelial cells have been used to study kinetic responses to infection with respiratory syncytial virus [27, 28], to our knowledge this is the first use of such cells for extended kinetic studies of responses to HRV infection.

Our data clearly show that similar peak intracellular and shed levels of HRV genomic RNA are observed regardless of the initial infectious dose of virus, although the peak of viral replication was delayed at lower infectious doses. Whether the peak levels of intracellular (and shed) virus observed with all infectious doses represent the maximal viral replication that can be supported by the cells is unclear. Given that the initial infectious material removed from the cells contains levels of HRV that are not distinguishable from the dose applied (not shown), it would appear that few virions are taken up by cells. Thus, it is unclear why a delay in replication is observed with lower doses. One could speculate that fewer cells are initially infected with lower doses and that it takes longer for all cells that can support replication to be infected. Regardless, a major observation from the current studies is that highly differentiated HBE can clear HRV-16 infection by $144 \mathrm{~h}$ after infection, regardless of the initial infectious dose used. This is reflected both by intracellular and shed virus levels. It should be noted that the general time course of shed virus in these cultures resembles that observed in nasal secretions following experimental HRV-16 infection of normal volunteers [17]. Overall, these data indicate that epithelial antiviral responses on their own are adequate to clear HRV-16 infections and that, while recruitment of inflammatory and immune cells to the airway mucosa in vivo may contribute to symptoms, these cells are not essential for virus clearance.

The generation of negative strand template is a prerequisite for transcription of new genomic RNA strands. The process of transcribing negative strands to genomic RNA leads to the formation of dsRNA. To examine the formation of dsRNA we used two complementary approaches. Immunofluorescence staining with a validated antibody to dsRNA showed perinuclear staining of dsRNA at $24 \mathrm{~h}$ post infection (the time of maximal intracellular virus load). This perinuclear localization is consistent with the concept that HRV replicates on membrane fragments derived from endoplasmic reticulum or golgi $[29,30]$.

Using $\beta$-tubulin as a marker for cilia, we observed that HRV replication was restricted to ciliated cells. This agrees with recent reports that both HRV-A and HRV-C strains selectively infect ciliated cells [31, 32]. Our assessment that $4-6 \%$ of total cells were positive for dsRNA staining is consistent with the observed focal, patchy infection observed in bronchial biopsies [21], and with the report that only $5-10 \%$ of $\mathrm{HBE}$ grown in submersion culture can be infected regardless of the initial infectious dose of HRV used [33].

To our knowledge there has been no prior quantitative assessment of the level of dsRNA achieved in airway epithelial cells infected with HRV. We examined absolute copy numbers of negative strand as a means to quantify 


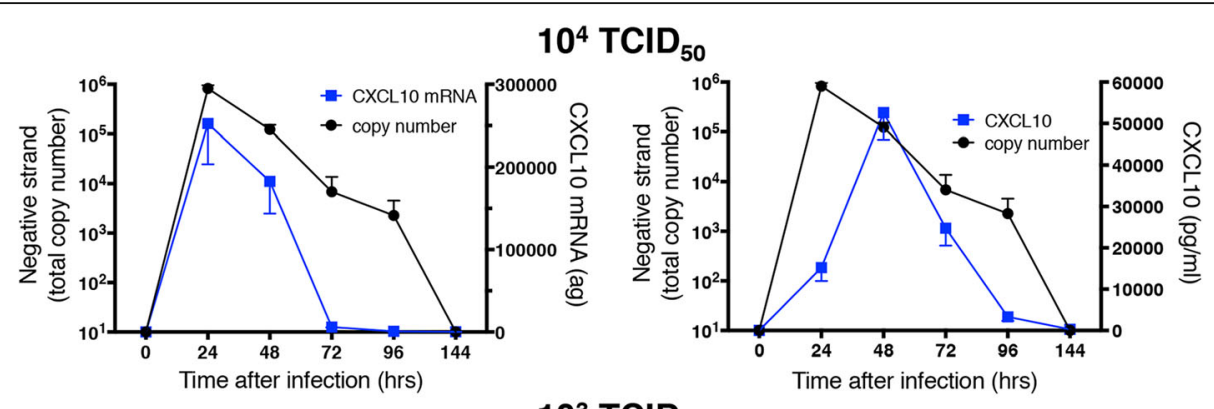

$10^{3} \mathrm{TCID}_{50}$
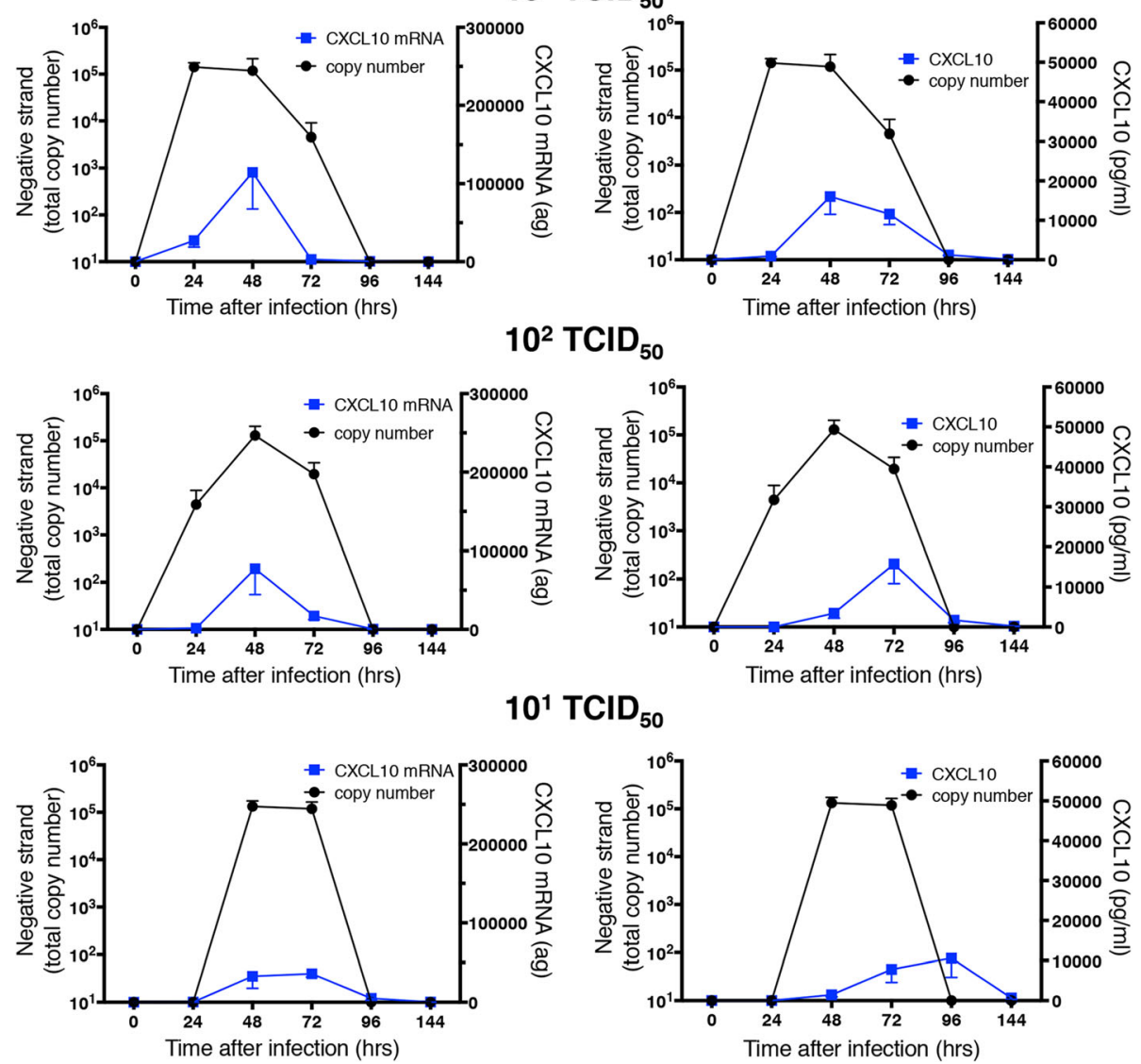

Fig. 8 Relationship between copy number of negative strand template (taken from Fig. 5) and mRNA or protein for CXCL10. For each initial infectious dose of HRV-16, copy number of negative stand template is shown relative to levels of CXCL10 mRNA (left panels) mRNA or basolateral protein release (right panels). Data are mean \pm SEM from 4 different HBE donors

dsRNA. Prior studies of single strand genome viruses have shown that conventional RT-PCR targeting the negative strand does not provide strand-specificity. The phenomenon of "false priming" yields signals even in the absence of primer during reverse transcription [34, 35], and studies using single strands generated by in vitro transcription from plasmids have shown that RT-PCR for negative strand is not specific in the presence of excess positive strand [36]. We therefore modified a previously published strategy [36], in which the primer for reverse transcription contains a non-viral sequence at the $5^{\prime}$ end of the specific sequence targeting the negative strand of HRV-16. This non-viral sequence is then used as a primer to selectively amplify the negative strand specific cDNA at the PCR stage. This technique showed that similar levels of negative strand (and, thus, presumably, dsRNA) were achieved regardless of the initial infectious dose, albeit with varying time-courses. This implies that a defined level of negative strand is required for optimal replication of genomic RNA. If the concept put forward for poliovirus that genomes that have not been translated cannot function as templates for negative strand synthesis $[37,38]$ also holds true for HRV, this would suggest that a defined level of virus 

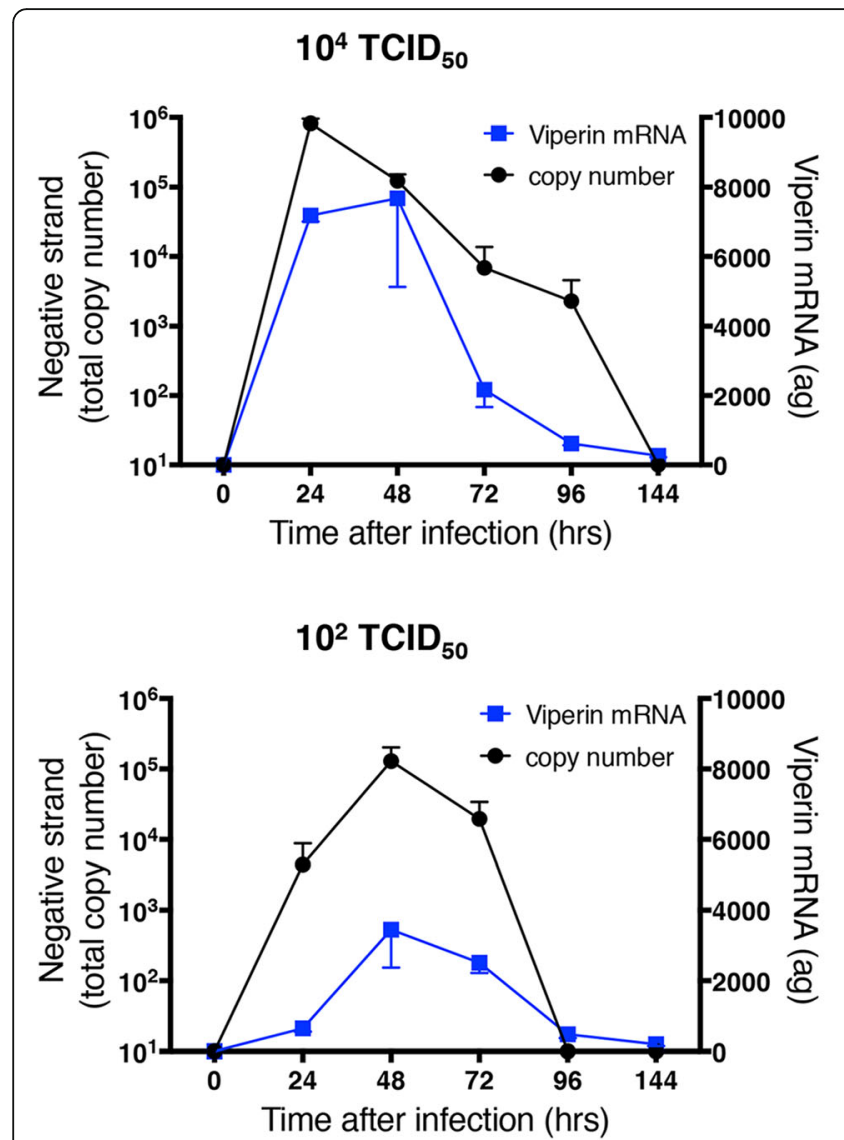
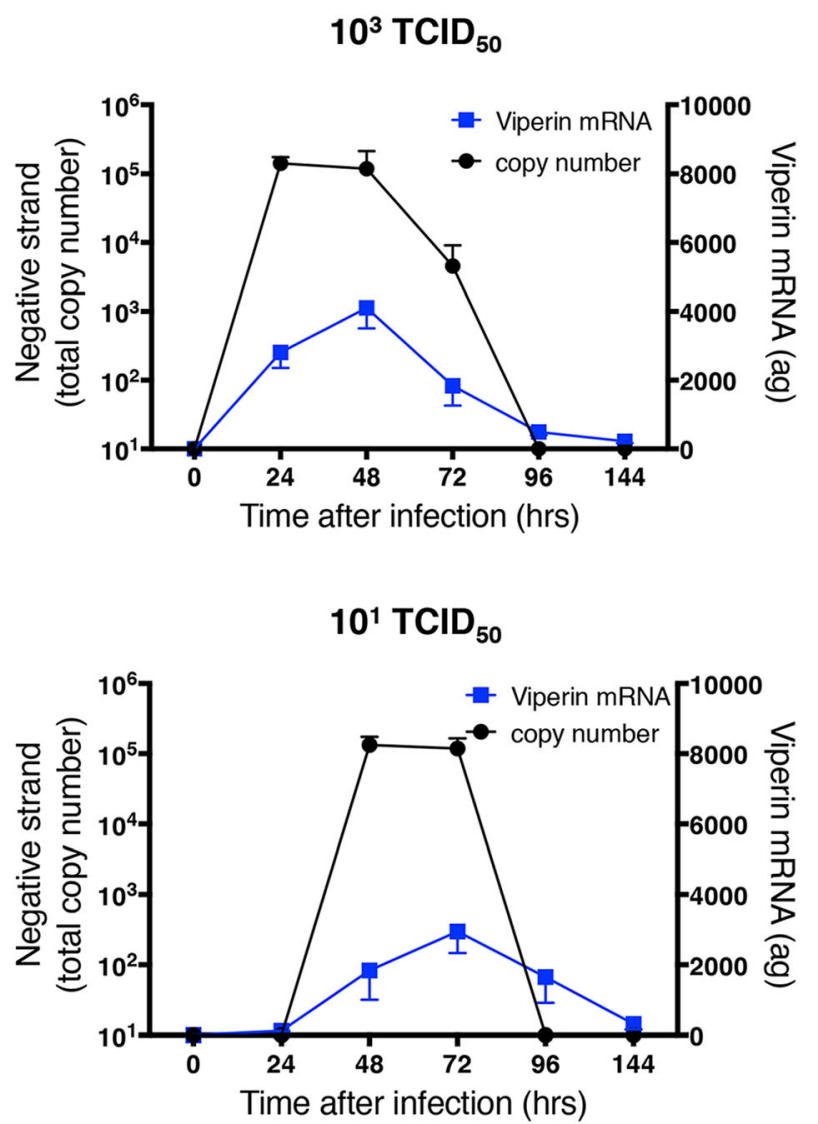

Fig. 9 Relationship between copy number of negative strand template (taken from Fig. 5) and mRNA for viperin. For each initial infectious dose of HRV-16, copy number of negative stand template is shown relative to levels of viperin mRNA Data are mean \pm SEM from 4 different HBE donors

polyprotein strands are translated after infection in order to support optimal viral replication. Given that copy numbers of negative strand were about 10,000-fold lower than those of positive strand, transcription of positive strand from template must be highly efficient. Our data differ from a previous report of a ratio of only about 70 positive strands per negative strand in cells infected with poliovirus, assessed using an RNase protection assay [39]. This difference may be due to specificity of the natural cell host (the cell type used in the prior poliovirus study was never defined), differences between viruses, or the sensitivity and specificity of the methods used.

The dsRNA generated during viral replication is recognized by pattern recognition receptors (PRRs) to induce innate immune responses. Studies have reported varying roles of the dsRNA receptors, toll-like receptor-3, retinoic acid inducible gene-I and melanoma differentiation associated gene- 5 in inducing epithelial responses to HRV infection [19, 40, 41]. Type I and type III IFNs are both produced by epithelial cells in response to viral infections but recent studies have indicated that type III IFNs, particularly IFN- $\lambda 1$, are the dominant IFNs produced by human airway epithelial cells in response to HRV infection [10, 42]. We confirmed this observation in highly differentiated epithelial cells, showing that induction of mRNA and protein for IFN- $\lambda 1$ are considerably higher than levels observed for IFN- $\beta$. Interestingly, however, despite the relatively constant level of negative strand template generated with each initial infectious dose of HRV-16, levels of mRNA and protein for type I and type III IFNs decreased markedly as the initial infectious dose of HRV decreased. Interestingly, levels of IFNs produced had no bearing on the time to HRV clearance, implying that neither of these types of IFNs control viral clearance. No IFNs were generated in cells exposed to HRV rendered replication deficient by exposure to UV light (not shown). Since HRV treated in this way can still engage its receptor, this implies that induction of IFNs requires viral replication and not just engagement of ICAM-1, the receptor for HRV-16. For each infectious dose of HRV-16, the kinetics, but not the quantity, of IFN induction mirrored that of negative strand template. Thus, the degree of induction of IFNs is not simply regulated by levels of dsRNA, as reflected by levels of negative strand. This implies that other factors 

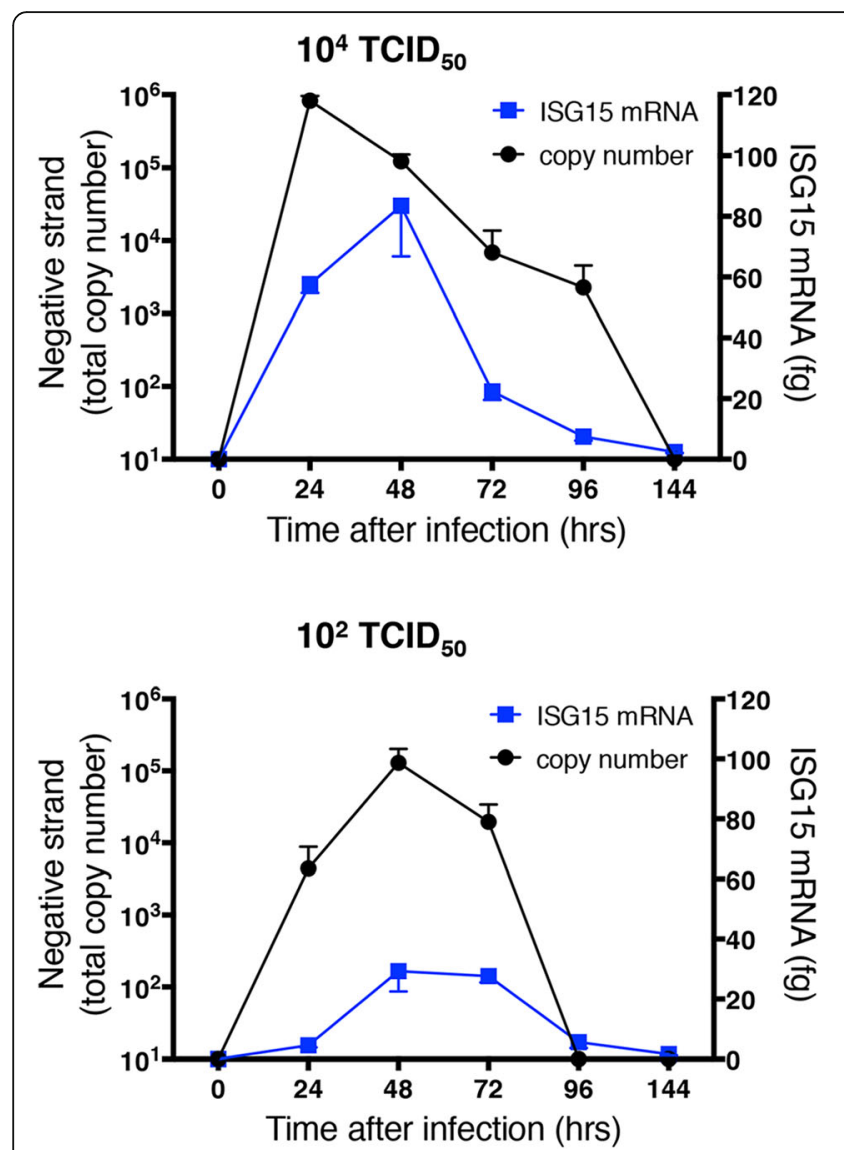

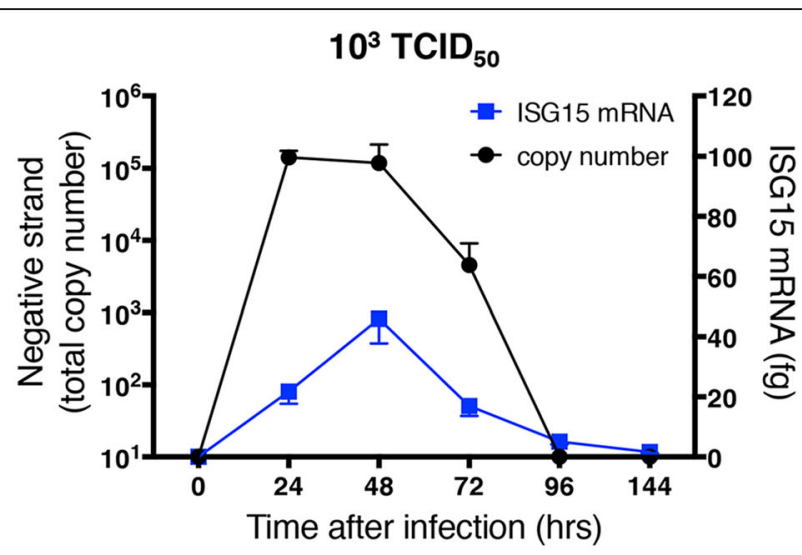

$10^{1} \mathrm{TCID}_{50}$

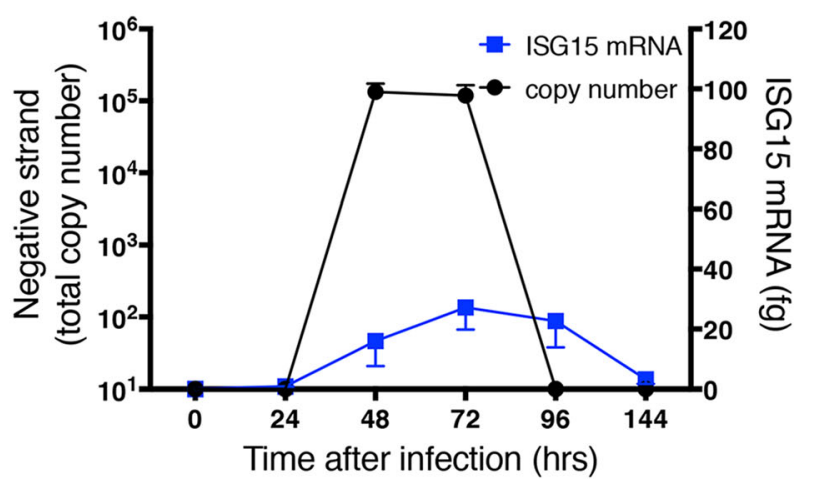

Fig. 10 Relationship between copy number of negative strand template (taken from Fig. 5) and mRNA for ISG15. For each initial infectious dose of HRV-16, copy number of negative stand template is shown relative to levels of ISG15 mRNA Data are mean \pm SEM from 4 different HBE donors

generated during the replication cycle must play a role. The identity of these factors is unknown but singlestranded RNA, other replications intermediates, or other components of the viral genome, may contribute. Induction of CXCL10 mRNA and protein closely mirrored the induction of IFNs, both in terms of kinetics and quantity. Since we have previously reported that induction of CXCL10 by HRV-16 is not mediated via IFN signaling [17], it may be that induction of both CXCL10 and IFNs occur via shared pathways. It is of interest that there was a different vectoriality of release for IFNs (mainly apical) and CXCL10 (mainly basolateral). We have also observed this for other epithelial mediators (not shown). At this point the reasons for these differences are unknown.

Interestingly, although viperin and ISG-15 mRNA levels were highest when infected with $10^{4} \mathrm{TCID}_{50}$ of HRV-16, levels were relatively constant at the three lower infectious doses. The persistence of mRNA expression for these two genes at lower infectious doses, despite the profound decline in IFN levels, suggest that their induction is not mediated by type I or type III IFNs. Although both viperin and ISG15 are usually referred to as members of the group of "IFN-stimulated genes" (ISGs), there is precedent that ISGs can be induced independently of IFNs. Such IFN-independent induction occurs via direct viral induction of key transcription factors, particularly members of the interferon regulatory factor (IRF) family. Thus, cells deficient in both type I and type III IFN receptors still showed induction of multiple ISGs in response to influenza infection [43]. Similarly, it has previously been show that viperin can be induced independently of IFN signaling via an IRF-1 mediated mechanism [44]. Consistent with this, we have previously shown robust induction of IRF1 and IRF-7 in HRV-infected human airway epithelial cells $[45,46]$, and have demonstrated that induction of ISG15 by HRV is dependent upon transcriptional control by IRF-1 [19].

Although textbooks frequently state that HRV virions escape cells via lysis, this is based on studies in HeLa cells. It has been known for years, however, that HRV infections in vivo do not cause overt epithelial cytotoxicity [47]. Consistent with this observation, no overt cell death was observed in our highly differentiated cultures of HBE upon infection with HRV and an intact epithelium was still observed at $144 \mathrm{~h}$ after HRV 
infection (Fig. 2). Histological integrity was not different compared to cells exposed to medium for $144 \mathrm{~h}$, or to epithelium prior to infection (Fig. 1a). We cannot rule out that death or shedding of a small percentage of cells occurs during infection, but if so, the epithelium either generates replacement cells or else adjacent cells expand to maintain an intact epithelium. In terms of alternative means for HRV to escape epithelial cells, there is precedent for HRV and other enterovirus species to leave other cell types via phosphatidylserine rich membrane vesicles with properties of either exosomes or autophagosomal like vesicles [48-50]. Additional studies will be required, however, to evaluate if this occurs in HRV infected highly differentiated HBE.

Our current studies used HRV-16, a member of the HRV-A genetic group of rhinoviruses that uses ICAM-1 to gain cell entry. We used HRV-16 because it is representative of a large number of HRV-A strains that also use ICAM-1, and has been commonly used for in vivo experimental infections. Nonetheless, we must avoid generalizing our data to all strains of HRV. Additional studies will be required to determine if HRV-A strains that use the low density lipoprotein as a receptor, or HRV-C strains that require cadherin related family member 3 to gain cell entry [51], show the same patterns of virus clearance, epithelial integrity, negative strand template expression and antiviral gene expression observed for HRV-16. It will also be of interest to determine if responses to a second consecutive infection, either with the same HRV strain or a different one, will show altered responses.

\section{Conclusions}

In summary, we demonstrate that HRV-16 infects a subset of ciliated cells in highly differentiated cultures of HBE. These HRV-16 infections are cleared without the need for immune cells, and the time to clearance does not depend on levels of IFNs. Regardless of initial infectious dose used, relatively constant levels of genomic and negative strand RNA are generated, albeit with varying kinetics. Copy numbers of negative-strand RNA are some 10,000-fold lower than numbers of positive (genomic) strands. Although relatively constant levels of negative strands are generated regardless of initial infectious dose, levels of type I and type III IFNs vary depending upon initial infectious dose, implying that factors other than levels of dsRNA regulate IFN induction. Patterns of viperin and ISG15 expression suggest they may be generated in an IFN-independent manner during HRV-16 infections. These data challenge a number of widely held paradigms generated from earlier studies in HeLa cells and emphasize the importance of appropriate cell context when performing experiments using HRV infections.

\section{Abbreviations}

ALI: Air-liquid interface; CXCL10: C-X-C chemokine ligand 10; dsRNA: doublestranded RNA; HBE: Human bronchial epithelial cells; HRV: Human Rhinovirus; IFN: Interferon; IRF: Interferon regulatory factor; ISG: Interferon stimulated gene; ISG15: Interferon stimulated gene of 15 kilodaltons; TCID 50 : 50\% tissue culture-infective dose

\section{Acknowledgements \\ Not applicable.}

\section{Authors' contributions}

SMW and DP conceived and designed the overall study. SMW, SW and ANM contributed original data. DP drafted the manuscript, which was reviewed, edited and approved by all authors.

\section{Funding}

This work was supported by a grant from the Natural Sciences and Engineering Research Council of Canada NSERC (funding reference number RGPIN-201803861). SMW was supported by an "Eyes High" Postdoctoral Scholarship from the University of Calgary. ANM is the recipient of a studentship from the Lung Association of Alberta \&Northwest Territories. DP is the recipient of a Tier 1 Canada Research Chair in Inflammatory Airway Diseases. Microscopy infrastructure was supported by the Canadian Foundation for Innovation-John R. Evans Leaders fund with matching support from the Alberta Enterprise and Advanced Education Research Capacity Program. The funders had no role in study design, data collection and interpretation, or the decision to submit the work for publication.

\section{Availability of data and materials}

The authors' unpublished data are available upon request.

\section{Ethics approval and consent to participate}

Normal human lungs not used for transplant were obtained from a tissue retrieval service (IIAM, Edison, NJ). Family members of donors gave consent for tissues to be used for research. Ethics approval to use human lung tissues was obtained from the Conjoint Health Research Ethics Board of the University of Calgary.

\section{Consent for publication}

Not applicable.

\section{Competing interests}

The authors declare that they have no competing interests.

Received: 23 April 2019 Accepted: 1 July 2019

Published online: 12 July 2019

\section{References}

1. Makela MJ, Puhakka T, Ruuskanen O, Leinonen M, Saikku P, Kimpimaki M, et al. Viruses and bacteria in the etiology of the common cold. J Clin Microbiol. 1998:36:539-42.

2. Johnston SL, Pattemore PK, Sanderson G, Smith S, Lampe F, Josephs L, et al. Community study of role of viral infections in exacerbations of asthma in 911 year old children. Br Med J. 1995;310:1225-8.

3. Kistler A, Avila PC, Rouskin S, Wang D, Ward T, Yagi S, et al. Pan-viral screening of respiratory tract infections in adults with and without asthma reveals unexpected human coronavirus and human rhinovirus diversity. J Infect Dis. 2007;196:817-25.

4. Seemungal T, Harper-Owen R, Bhowmik A, Moric I, Sanderson G, Message S, et al. Respiratory viruses, symptoms and inflammatory markers in acute exacerbations and stable chronic obstructive pulmonary disease. Am J Respir Crit Care Med. 2001;164:1618-23.

5. Arruda E, Boyle TR, Winther B, Pevear DC, Gwaltney JM Jr, Hayden FG. Localization of human rhinovirus replication in the upper respiratory tract by in situ hybridization. J Infect Dis. 1995;171:1329-33.

6. Papadopoulos NG, Bates PJ, Bardin PG, Papi A, Leir SH, Fraenkel DJ, et al. Rhinoviruses infect the lower airways. J Infect Dis. 2000;181:1875-84.

7. Vareille M, Kieninger E, Edwards MR, Regamey N. The airway epithelium: soldier in the fight against respiratory viruses. Clin Microbiol Rev. 2011; 24:210-29. 
8. Leigh R, Proud D. Modulation of epithelial biology by rhinovirus infection: role in inflammatory airway diseases. Future Virol. 2011;6:375-86.

9. Proud D, Turner RB, Winther B, Wiehler S, Tiesman JP, Reichling TD, et al. Gene expression profiles during in vivo human rhinovirus infection: insights into the host response. Am J Respir Crit Care Med. 2008;178:962-8.

10. Proud D, Hudy MH, Wiehler S, Zaheer RS, Amin MA, Pelikan JB, et al. Cigarette smoke modulates expression of human rhinovirus-induced airway epithelial host defense genes. PLoS One. 2012;7:e40762.

11. Blaas D. Viral entry pathways: the example of common cold viruses. Wien Med Wochenschr. 2016;166:211-26.

12. van der Linden $L$, Wolthers KC, van Kuppeveld FLM. Replication and inhibitors of enteroviruses and perechoviruses. Viruses. 2015;7:4529-62.

13. Takeuchi O, Akira S. Innate immunity to virus infection. Immunol Rev. 2009; 227:75-86.

14. Jacobs SE, Lamson DM, St George K, Walsh TJ. Human rhinoviruses. Clin Microbiol Rev. 2013;26:135-62.

15. Churchill L, Chilton FH, Resau JH, Bascom R, Hubbard WC, Proud D. Cyclooxygenase metabolism of endogenous arachidonic acid by cultured human tracheal epithelial cells. Am Rev Respir Dis. 1989;140:449-59.

16. Sanders SP, Siekierski ES, Porter JD, Richards SM, Proud D. Nitric oxide inhibits rhinovirus-induced cytokine production and viral replication in a human respiratory epithelial cell line. J Virol. 1998;72:934-42.

17. Spurrell JCL, Wiehler S, Zaheer RS, Sanders SP, Proud D. Human airway epithelial cells produce IP-10 (CXCL10) in vitro and in vivo upon rhinovirus infection. Am J Physiol Lung Cell Mol Physiol. 2005;289:L85-95.

18. Schönborn J, Oberstraß J, Breyel E, Tittgen J, Schumacher J, Lukacs N. Monoclonal antibodies to double-stranded RNA as probes of RNA structure in crude nucleic acid extracts. Nucleic Acids Res. 1991;19:2993-3000.

19. Zaheer RS, Wiehler S, Hudy MH, Traves SL, Pelikan JB, Leigh R, et al. Human rhinovirus-induced ISG15 selectively modulates epithelial antiviral immunity. Mucosal Immunol. 2014;7:1127-38.

20. Scherer WF, Syverton JT, Gey GO. Studies on the propagation in vitro of poliomyelitis viruses. IV. Viral multiplication in a stable strain of human malignant epithelial cells (strain HeLa) derived from an epidermoid carcinoma of the cervix. J Exp Med. 1953;97:695-710.

21. Mosser AG, Vrtis R, Burchell L, Lee W-M, Dick CR, Weisshaar E, et al. Quantitative and qualitative analysis of rhinovirus infection in bronchial tissues. Am J Respir Crit Care Med. 2005;171:645-51.

22. Subauste MC, Jacoby DB, Richards SM, Proud D. Infection of a human respiratory epithelial cell line with rhinovirus. Induction of cytokine release and modulation of susceptibility to infection by cytokine exposure. J Clin Invest. 1995;96:549-57.

23. Schroth MK, Grimm E, Frindt P, Galagan DM, Konno S-I, Love R, et al. Rhinovirus replication causes RANTES production in primary bronchial epithelial cells. Am J Respir Cell Mol Biol. 1999;20:1220-8.

24. Sanders SP, Siekierski ES, Richards SM, Porter JD, Imani F, Proud D. Rhinovirus infection induces expression of type 2 nitric oxide synthase in human respiratory epithelial cells in vitro and in vivo. J Allergy Clin Immunol. 2001:107:235-43.

25. Lopez-Souza N, Favoreto S, Wong H, Ward T, Yagi S, Schnurr D, et al. In vitro susceptibility to rhinovirus infection is greater for bronchial than for nasal airway epithelial cells in human subjects. J Allergy Clin Immunol. 2009;123:1384-90.

26. Bai J, Smock SL, Jackson GRJ, Maclsaac KD, Huang Y, Mankus C, et al. Phenotypic responses of differentiated asthmatic human airway epithelial cultures to rhinovirus. PLoS One. 2015;10:e0118286.

27. Villenave R, Thavagnanam S, Sarlang S, Parker J, Douglas I, Skibinski G, et al. In vitro modeling of respiratory syncytial virus infection of pediatric bronchial epithelium, the primary target for infection in vivo. Proc Natl Acad Sci U S A. 2012;109:5040--45.

28. Broadbent L, Villenave R, Guo-Parke H, Douglas I, Shields MD, Power UF. In vitro modeling of RSV infection and cytopathogenesis in well-differentiated human primary airway epithelial cells (WD-PAECs). Methods Mol Biol. 2016; 1442:119-39.

29. Richards AL, Jackson WT. Behind closed membranes: the secret lives of piconaviruses? PLoS Pathog. 2013;9:e1003262.

30. Mousnier A, Swieboda D, Pinto A, Guedán A, Rogers AV, Walton R, et al. Human rhinovirus 16 causes golgi apparatus fragmentation without blocking protein secretion. J Virol. 2014;88:11671-85.

31. Jakiela B, Gielicz A, Plutecka H, Hubalewska-Mazgaj M, Mastalerz L, Bochenek $\mathrm{G}$, et al. Th2-type cytokine-induced mucus metaplasia decreases susceptibility of human bronchial epithelium to rhinovirus infection. Am J Respir Cell Mol Biol. 2014;51:229-41.

32. Griggs TF, Bochkov YA, Basnet S, Pasic TR, Brockman-Schneider RA, Palmenberg AC, et al. Rhinovirus C targets ciliated airway epithelial cells. Respir Res. 2017;18:84.

33. Mosser AG, Brockman-Schneider R, Amineva S, Burchell L, Sedgewick JB, Busse WW, et al. Similar frequency of rhinovirus-infectable cells in upper and lower airway epithelium. J Infect Dis. 2002;185:734-43.

34. Lanford RE, Sureau C, Jacob JR, White R, Fuerst TR. Demonstration of in vitro infection of chimpanzee hepatocytes with hepatitis C virus using strandspecific RT/PCR. Virology. 1994;202:606-14.

35. Tuiskunen A, Leparc-Goffert I, Boubis L, Monteil V, Klingström J, Tolou HJ, et al. Self-priming of reverse transcriptase impairs strand-specific detection of dengue virus RNA. J Gen Virol. 2010;91:1017-27.

36. Vashist $S$, Urena L, Goodfellow I. Development of a strand specific real-time RT-qPCR assay for the detection and quantification of murine norovirus RNA. J Virol Methods. 2012;184:69-76.

37. Collis PS, O'Donnell BJ, Barton DJ, Rogers JA, Flanegan JB. Replication of poliovirus RNA and subgenomic RNA transcripts in transfected cells. J Virol. 1992:66:6480-8.

38. Novak JE, Kirkegaard K. Coupling between genome translation and replication in an RNA virus. Genes Dev. 1994;8:1726-37.

39. Novak JE, Kirkegaard K. Improved method for detecting poliovirus negative strands used to demonstrate specificity of positive-strand encapsidation and the ratio of positive to negative strands in infected cells. J Virol. 1991;65:3384-7.

40. Slater L, Bartlett NW, Haas JJ, Zhu J, Message SD, Walton RP, et al. Coordinated role of TLR-3, RIG-I and MDA5 in the innate response to rhinovirus in bronchial epithelium. PLoS Pathog. 2010;6:e1001178.

41. Hudy MH, Traves SL, Proud D. Transcriptional and epigenetic modulation of human rhinovirus-induced CXCL10 production by cigarette smoke. Am J Respir Cell Mol Biol. 2014;50:571-82.

42. Khaitov MR, Laza-Stanca V, Edwards MR, Walton RP, Rohde G, Contoli M, et al. Respiratory virus induction of alpha-, beta, and lambda-interferons in bronchial epithelial cells and peripheral blood mononuclear cells. Allergy. 2009;64:375-86.

43. Schmid S, Mordstein M, Kochs G, García-Sastre A, tenOever BR. Transcription factor redundancy ensures induction of the antiviral state. J Biol Chem. 2010;285:42013-22.

44. Stirnweiss A, Ksienzyk A, Klages K, Rand U, Grashoff M, Hauser H, et al. IFN regulatory factor-1 bypassess IFN-mediated antiviral effects through viperin gene induction. J Immunol. 2010;184:5179-85.

45. Koetzler R, Zaheer RS, Wiehler S, Holden NS, Giembycz MA, Proud D. Nitric oxide inhibits human rhinovirus-induced transcriptional activation of CXCL10 in airway epithelial cells. J Allergy Clin Immunol. 2009;123:201-8.

46. Bosco A, Wiehler S, Proud D. Interferon regulatory factor 7 regulates airway epithelial cell responses to human rhinovirus infection. BMC Genomics. 2016;17:76.

47. Winther B, Brofeldt S, Christensen B, Mygind N. Light and scanning electron microscopy of nasal biopsy material from patients with naturally acquired common colds. Acta Otolaryngol (Stockh). 1984;97:309-18.

48. Chen Y-H, Du W, Hagemeijer MA, Takvorian PM, Pau C, Cali A, et al. Phosphatidylserine vesicles enable efficient en bloc transmission of enteroviruses. Cell. 2015;160:619-30.

49. Longatti $\mathrm{A}$. The dual role of exosomes in hepatitis a and $\mathrm{C}$ virus transmission and viral immune activation. Viruses. 2015;7:6707-15.

50. Robinson SM, Tsueng G, Sin J, Mangale V, Rahawi S, Mclntyre LL, et al. Coxsackievirus B exits the host cell in shed microvesicles displaying autophagosomal markers. PLoS Pathog. 2014;10:e1004045.

51. Bochkov YA, Watters K, Ashraf S, Griggs TF, Devries MK, Jackson DJ, et al. Cadherin-related family member 3 , a childhood asthma susceptibility gene product, mediates rhinovirus $\mathrm{C}$ binding and replication. Proc Natl Acad Sci U S A. 2015;112:5485-90

\section{Publisher's Note}

Springer Nature remains neutral with regard to jurisdictional claims in published maps and institutional affiliations. 